\title{
Estado-avaliador e a reforma do Ensino Médio no Brasil: influências e confluências
}

Fabiana Teixeira Marcelino

Instituto Federal de Educação, Ciência e Tecnologia do Rio Grande do Norte (IFRN)

Shilton Roque dos Santos

Instituto Federal de Educação, Ciência e Tecnologia do Rio Grande do Norte (IFRN)

Márcio Adriano de Azevedo

Instituto Federal de Educação, Ciência e Tecnologia do Rio Grande do Norte (IFRN)

Lenina Lopes Soares Silva

Instituto Federal de Educação, Ciência e Tecnologia do Rio Grande do Norte (IFRN)

\begin{abstract}
Desde os anos 1990, vários Estados, independentemente de suas orientações políticoideológicas, têm participado ou interferido ativamente na construção de um sistema de indicadores de avaliação comparada internacionalmente e em larga escala. Esse tem como principais consequências a legitimação de discursos e a aquisição de uma certa imunidade ou indiferença às realidades e especificidades nacionais quando da formulação e implementação de políticas públicas. Este trabalho tem como objetivo analisar as influências e confluências da reforma do Ensino Médio, pela Lei Federal no 13.415/2017, no contexto do Estado-avaliador no Brasil, adotando-se procedimentos teórico-metodológicos como revisão bibliográfica e documental, análise de instrumentos de avaliação da Educação Básica, tendo em destaque o Ensino Médio (o Ideb e o Enem), além da Medida Provisória no 746/2016. Concluímos que a reforma vem para destacar a meritocracia na educação brasileira, acentuando o elemento de competitividade característico da ideologia neoliberal, confluindo para uma educação que reforça as desigualdades sociais no país.
\end{abstract}

Palavras-chave: política educacional, avaliação de políticas públicas, indicador educacional, ensino médio, desigualdade social, meritocracia

[Artigo recebido em 15 de março de 2017. Aprovado em 26 de fevereiro de 2019.] 


\section{Estado Evaluador y la reforma de la Enseñanza Secundaria em Brasil: influencias y confluencias}

Desde los años 1990, varios Estados independientemente de sus orientaciones políticoideológicas han participado o interferido activamente en la construcción de un sistema de indicadores de evaluación comparada internacionalmente ya gran escala. Este tiene como principales consecuencias la legitimación de discursos y la adquisición de una cierta inmunidad o indiferencia a las realidades y especificidades nacionales en la formulación e implementación de políticas públicas. Este trabajo tiene como objetivo analizar las influencias y confluencias de la reforma de la enseñanza media por la Ley Federal $n$ 으 13.415/2017, en el contexto del Estado-Evaluador - en Brasil, adoptando procedimientos teórico-metodológicos como revisión bibliográfica y documental, análisis de instrumentos de análisis la evaluación de la Educación Básica, teniendo en destaque la Enseñanza Media (el Ideb y el Enem), además de la Medida Provisional no 746/2016. Concluimos que la Reforma viene para destacar la meritocracia en la educación brasileña, acentuando el elemento competitividad característico de la ideología neoliberal, confluyendo hacia una educación que refuerza las desigualdades sociales en el país.

Palabras clave: política educativa, evaluación de políticas públicas, indicador educativo, enseñanza media, desigualdad social, meritocracia

\section{State-evaluator the High school reform Secondary Education in Brazil: confluences e influences}

Since the 1990s, several states regardless of their political-ideological orientations have participated or actively interfered in building a system of internationally and on a large scale comparative assessment indicators. This has as main consequences the legitimacy of speeches and the acquisition of a certain immunity or indifference to national realities and specificities when formulating and implementing public policies. This study aims to analyze the influences and confluences of the high school reform by Federal Law no 13.415/2017, in the context of the State-Evaluator - in Brazil, adopting theoretical and methodological procedures as bibliographical and documentary review, analysis of instruments of evaluation of Basic Education, with emphasis on Secondary Education (Ideb and Enem), in addition to Provisional Measure no 746/2016. We conclude that the Reformation comes to highlight meritocracy in Brazilian education, accentuating the element of competitiveness characteristic of neoliberal ideology, converging to an education that reinforces social inequalities in the country.

Keywords: educational policy, public policy evaluation, educational indicator, high school, social inequality, meritocracy 


\section{Introdução}

O presente artigo tem como proposta discutir a implantação da reforma do Ensino Médio a partir da Lei Federal no 13.415, de 16 de fevereiro de 2017, que altera a Lei no 9.394, de 20 de dezembro de 1996, que dispõe sobre as Diretrizes e Bases da Educação Nacional; a Lei no 11.494, de 20 de junho 2007, que regulamenta o Fundo de Manutenção e Desenvolvimento da Educação Básica e de Valorização dos Profissionais da Educação; a Consolidação das Leis do Trabalho (CLT), aprovada pelo Decreto-Lei no 5.452, de 1으 de maio de 1943; e o Decreto-Lei no 236, de 28 de fevereiro de 1967; bem como revoga a Lei № 11.161, de 5 de agosto de 2005, e institui a Política de Fomento à Implementação de Escolas de Ensino Médio em Tempo Integral.

A perspectiva de discussão é analisar a reforma sob a ótica da concepção do Estado-avaliador de Afonso $(1999,2013)$, problematizando a ideia de inovação, trazida pela proposta da reforma do Ensino Médio.

Para a realização do trabalho, adotamos procedimentos teórico-metodológicos, tais como: revisão bibliográfica em Santos (2010) e Afonso $(1999,2013)$ e análise documental, como a análise dos instrumentos de avaliação da Educação Básica e do Ensino Médio, presentes principalmente na proposta dos sistemas dos Indicadores de Desenvolvimento da Educação Básica (Ideb) e do Exame Nacional do Ensino Médio (Enem), além da legislação supracitada e da Medida Provisória no 746/2016, que regulamenta a reforma do Ensino Médio no Brasil.

\section{O Estado brasileiro e a formação do Estado-avaliador}

Para tratar do Estado-avaliador no contexto brasileiro e da reforma do Ensino Médio nesse contexto, empreendemos estudos em Santos (2010) e Afonso (1999, 2013), na perspectiva de construir um encadeamento lógico que permita compreender o Estado brasileiro no âmbito de formação dos Estados como avaliadores de suas ações.

Santos (2010) indica que é possível perceber uma série de contradições entre recentes concepções de Estado: alguns criticam a tendência do Estado de penetrar ou mesmo absorver a sociedade civil de formas cada vez mais autoritárias; outros apontam que o Estado é crescentemente ineficaz, cada vez mais incapaz de desempenhar as funções de que se incumbe. Todavia, é mister considerar que é o Estado, seja de forma autoritária ou ineficaz, que regulamenta suas políticas, advindo desse status as concepções contraditórias que sobre ele incidem, principalmente no momento em que propõe descontinuidades de políticas públicas. 
Para Santos (2010), três causas podem explicar essas contradições nas concepções de Estado. A primeira é o fato de se continuar a analisar os processos de transformação social do fim do século 20 com recurso a quadros conceituais desenvolvidos no século 19 e adequados aos processos sociais então em curso. $A$ segunda causa explica-se porque o Estado-nação continua a predominar enquanto unidade de análise e suporte lógico da investigação, o que dificulta a percepção da autonomia crescente de estruturas e processos locais típicos de unidades menores ou dos movimentos globais. Como terceira causa, percebe-se que a teoria sociológica continua a ser derivada das experiências sociais e inclinada a suscitar generalizações ilegítimas - podendo-se dizer que, "[...] quanto mais geral é a teoria sociológica, maior é a probabilidade de ser baseada na experiência social e histórica dos países centrais e enviesada a favor destes últimos (o viés do centrocentrismo)" (SANTOS, 2010, p. 116). Dessas três causas, a primeira e a terceira se enquadram nos pressupostos deste trabalho, visto que se centram na questão do quadro conceitual, que, qualquer que tenha sido sua utilidade em outros tempos, no momento presente se configura como um obstáculo teórico ao avanço do conhecimento sobre Estado e sociedade, notadamente quando trata de políticas educacionais.

Ao discutir as concepções de Estado, e as suas contradições, Santos (2010) caminha para o debate sobre a distinção entre Estado e sociedade civil, o que pode ser uma importante reflexão para as discussões sobre reforma do Ensino Médio tendo em vista que essa implica na formação dos jovens de 14 a 17 anos que necessitam de escola pública de qualidade. Para esse autor,

[...] o que está verdadeiramente em causa na "reemergência da sociedade civil" no discurso dominante é um reajustamento estrutural das funções do Estado por via do qual o intervencionismo social, interclassista, típico do Estado-Providência ${ }^{1}$, é parcialmente substituído por um intervencionismo bicéfalo, mais autoritário face ao operariado e a certos sectores das classes médias (por exemplo, a pequena burguesia assalariada) e mais diligente no atendimento das exigências macro-econômicas da acumulação de capital (sobretudo do grande capital) (SANTOS, 2010, p. 124).

Na mesma linha de pensamento, Afonso (2013) cita Roger Dale (2004) quando o mesmo discorre acerca do argumento central de que as instituições do Estadonação, e o próprio Estado, devem ser vistos como essencialmente moldados através de uma ideologia do mundo dominante, e não como criações nacionais autônomas e

\footnotetext{
${ }^{1}$ Diferenciando de Estado-social, Santos (1987) define Estado-providência como a forma política do Estado nos países capitalistas avançados pós-socialismo. Seria o resultado do compromisso teorizado por Keynes entre o Estado, o capital e o trabalho, nos termos do qual os capitalistas renunciam a parte de sua autonomia e dos seus lucros (no curto prazo) e os trabalhadores a parte de suas reinvindicações, sendo esse acordo gerido pelo Estado.
} 
únicas. Sendo assim, as políticas de Estado também são moldadas por essas culturas e normas "universais". Essa argumentação vai conformar os princípios norteadores das avaliações em larga escala que confluem para que sejam desconsideradas as singularidades e especificidades das realidades locais/nacionais.

Outro ponto destacado por Afonso (2013) é a ideia de modernização, que, segundo Sztompka (2005), pode ser, entre outras coisas, sinônimo de mudança social progressiva. Porém, o que está subjacente é uma concepção evolutiva e unilinear da mudança social, indicando uma concepção de desenvolvimento que tem como padrão de referência as sociedades capitalistas mais avançadas.

Tendo em vista esses dois pontos, Afonso (2013) identifica duas fases do Estadoavaliador ${ }^{2}$ : uma primeira fase cuja característica é que a adoção de políticas de avaliação depende em grande parte de uma expressiva autonomia relativa dos Estados. Nessa fase, em um contexto anterior à verificação do fracasso do "socialismo real", o Estado-avaliador teve uma conotação político-ideológica relacionada com o neoconservadorismo e o neoliberalismo emergentes, com uma agenda fortemente preocupada com a afirmação e manutenção mais explícita da supremacia educacional de alguns países sobre outros, com vistas a reforçar internamente a identidade nacional e, externamente, a procura de vantagens competitivas, num mundo em que o processo de globalização estava em crescimento. Essa fase ainda apontaria uma globalização de baixa intensidade.

Numa segunda fase, o Estado-avaliador passa a ser confrontado de forma mais clara com os efeitos externos sobre as políticas educativas. Nos anos 1990, vários Estados, independentemente de suas orientações político-ideológicas, participaram ou interferiram ativamente na construção de sistemas de indicadores e de avaliação comparada internacional em larga escala, cujas principais consequências são a legitimação de discursos e a aquisição de uma certa imunidade ou indiferença às realidades e especificidades nacionais.

Assim, certas formas de avaliação comparada, como o Programme for Internacional Student Assesment (PISA) ${ }^{3}$, espalham-se mundialmente porque muitos países periféricos continuam a perseguir objetivos de modernização, seduzidos pelo progresso ou desenvolvimento relacionáveis com agendas educacionais de países capitalistas centrais. A inculcação nos indivíduos e governos da crença de que não

\footnotetext{
${ }^{2}$ Afonso (2013) indica que a expressão Estado-avaliador foi proposta para chamar atenção para as mudanças no ensino superior e passou a ser usada e convocada em muitos outros domínios das políticas públicas educativas.

${ }^{3}$ O Programme for Internacional Student Assesment (PISA) é hoje um dos principais meios de ação da Organização para a Cooperação e Desenvolvimento Econômico (OCDE) no setor educativo e constitui também um importante instrumento de regulação baseado no conhecimento, segundo Afonso (2013). Para aprofundar, sugerimos ainda Afonso (2009) e Ravitch (2011).
} 
há alternativas para além do capitalismo democrático liberal é não só congruente com o a-historicismo vigente nas últimas décadas quando se trata de políticas educacionais, como também é congruente com a adoção de orientações políticas, culturais e econômicas que parecem pressupor um único padrão de referência - o mercado como modelo.

No campo da educação, aí se distingue um engodo: não vivemos num mundo que se moderniza, mas num mundo capitalista. O mundo se move não por progresso, mas pela necessidade de lucro. Afonso (2013) explica, por fim, que é sabido que os países centrais só têm interesse na subida dos níveis educacionais dos países periféricos quando isso ocorre dentro dos limites desejados e necessários para a contínua expansão do sistema capitalista mundial, o que significa: a) qualificação de mão de obra, enquanto exército de reserva qualificado; b) ou como condição para preparar e integrar novos consumidores no mercado mundial. Sinaliza ainda que devemos nos interrogar sobre o grande protagonismo de organizações internacionais como a Organização para a Cooperação e Desenvolvimento Econômico (OCDE) e o Banco Mundial, que cada vez mais são aceitos como inquestionáveis e supostamente imprescindíveis na formulação e estruturação de políticas educativas. Aqui se visualiza o que seria uma terceira fase, ou melhor, um pós-Estado-avaliador: uma expansão de lógicas neoliberais de transnacionalização da educação, com ênfase na privatização, mercadorização e mercantilização.

Afonso (1999) nos convida a compreender as mudanças econômicas e políticas que vêm ocorrendo no mundo e no Brasil, com o renascimento do movimento conservador e neoliberal. Esse movimento traz implicações diretas nas reformulações das políticas educacionais. O autor destaca a emergência das políticas da nova direita nos anos 1980 e 1990 nos países capitalistas centrais, que traz como característica a combinação da defesa da livre economia com a defesa da autoridade do Estado. Aqui se constata um paradoxo: o Estado precisa ser forte e limitado ao mesmo tempo. No capitalismo avançado, o Estado autoritário se torna necessário para vigiar a imposição dessa nova ordem representada pelo mercado. Essa combinação de Estado e elementos do mercado no domínio público, associada a governos da nova direita, aumenta o controle sobre currículos e exames nacionais e aumenta a publicização dos resultados escolares, levando a pressões competitivas no sistema educativo.

O governo do Presidente Michel Temer identificou a avaliação como forma de controlar as despesas públicas, mudar a cultura do setor público e alterar as fronteiras e a definição das esferas de atividade pública e privada, dando, assim, ênfase à avaliação de resultados e desvalorização da avaliação de processos. É aí que 
emerge o Estado-avaliador, tendo a avaliação como estratégia de responsabilização e prestação de contas públicas.

Na educação os processos de avaliação conduzidos sob essa perspectiva acabam sendo mais importantes do que os processos pedagógicos em si. Afonso (1999, 2012) indica que o ideal é substituir a avaliação normativa pela formativa ${ }^{4}$, ou seja: trazer para os processos avaliativos uma visão que contraponha a lógica da emancipação à lógica da regulação.

Assim, para fundamentar uma política avaliativa alternativa, Afonso (1999, 2012) defende relocalizar a avaliação formativa dentro de um projeto de educação emancipatória; colocar a avaliação formativa como eixo fundamental na articulação entre o Estado e a comunidade; utilizar formas de avaliação pedagógica mais congruentes com o princípio da comunidade ${ }^{5}$ e com o pilar da emancipação; e realizar uma ação pedagógica estruturada na base de relações de reciprocidade intersubjetivamente validada.

Afonso (1999) destaca também que, em um Estado fragilizado na educação, a desvalorização da avaliação formativa, num contexto de aumento de uma cultura social de discriminação e de ausência de condições para a realização de uma escola básica democrática com qualidade científica e pedagógica, é notória.

Nesse sentido, Afonso se aproxima da perspectiva de Silva (2016), que diz que é necessário assumir

[...] a concepção de política como meio de inclusão social dos excluídos, ou seja, a concepção dialética que compreende as políticas educacionais como possibilidades coletivas constituídas para minimizar os impactos e efeitos das ações decorrentes do Estado capitalista (SILVA, 2016, p. 27).

Todavia, não é esta a concepção que subjaz à reforma do Ensino Médio, como se pode observar pelos documentos reguladores.

O Instituto Nacional de Estudos e Pesquisas Educacionais Anísio Teixeira (Inep), autarquia federal do Ministério da Educação (MEC), é responsável por promover estudos, pesquisas e avaliações sobre o sistema educacional brasileiro com o objetivo de subsidiar a formulação e implementação de políticas públicas na área educacional e produzir informações aos gestores, pesquisadores, educadores

\footnotetext{
${ }^{4}$ Ramos e Schabrach (2012) definem que a avaliação pode ser formativa, de acordo com a natureza da avaliação. Sendo formativa, a avaliação é relacionada com a formação do programa, e voltada para análise e produção de informações sobre a implementação.

${ }^{5}$ Afonso (1999) dialoga com Santos (1991), quando retoma os três princípios: Estado, mercado e comunidade. Dos três, o princípio da comunidade é o mais bem colocado para instaurar uma dialética positiva com o pilar da emancipação, e restabelecer assim a vinculação da regulação e da emancipação.
} 
e público em geral. Entre as avaliações realizadas, duas se aproximam mais do objetivo deste artigo: o Ideb e o Enem, consideradas avaliação em larga escala.

Segundo o site institucional do Inep ${ }^{6}$, o Ideb reúne, em um só indicador, de um lado, os resultados do fluxo escolar e as médias de desempenho das avaliações, calculados a partir dos dados sobre aprovação escolar, obtidos no Censo Escolar; e, de outro lado, as médias de desempenho nas avaliações do Inep, por meio do Sistema de Avaliação da Educação Básica (Saeb) - para as unidades da Federação e para o país - e da Prova Brasil - para os municípios. Ainda segundo o site,

O IDEB agrega ao enfoque pedagógico dos resultados das avaliações em larga escala do INEP a possibilidade de resultados sintéticos, facilmente assimiláveis, e que permitem traçar metas de qualidade educacional para os sistemas. O índice varia de zero a 10 e a combinação entre fluxo e aprendizagem tem o mérito de equilibrar as duas dimensões: se um sistema de ensino retiver seus alunos para obter resultados de melhor qualidade no SAEB ou Prova Brasil, o fator fluxo será alterado, indicando a necessidade de melhoria do sistema. Se, ao contrário, o sistema apressar a aprovação do aluno sem qualidade, o resultado das avaliações indicará igualmente a necessidade de melhoria do sistema (INSTITUTO NACIONAL DE ESTUdOS E Pesquisas Educacionais Anísio Teixeira, 2017).

Já o Enem, criado em 1998, tem o objetivo de avaliar o desempenho do estudante ao final do Ensino Médio, buscando contribuir para a melhoria na qualidade da escolarização. Desde 2004, passou também a ser utilizado como mecanismo de seleção para o ingresso no Ensino Superior, seja utilizando-se resultados do Enem como fase única de seleção ou combinando-os com os próprios processos seletivos de cada universidade, "assim democratizando as oportunidades de acesso às vagas oferecidas por Instituições Federais de Ensino Superior (Ifes)" (INSTITUTO NACIONAL de Estudos e Pesquisas Educacionais Anísio Teixeira, 2017).

Nos termos da Portaria MEC no 10, de 20 de maio de 2012, e da Portaria Inep no 179 , de 28 de abril de 2014, até $2016^{7}$ o participante do Enem interessado em obter o certificado de conclusão do Ensino Médio ou a declaração parcial de proficiência poderia fazer a solicitação às instituições certificadoras que são responsáveis pela emissão desses documentos com base nos resultados de desempenho no Enem: secretarias de estado de educação e os institutos federais de educação, ciência e tecnologia, mediante assinatura do termo de adesão. O participante deveria

${ }^{6}$ http://portal.inep.gov.br/web/guest/educacao-basica Acesso em: 11/mar/2017.

${ }^{7}$ Foi noticiado em 24/11/2016 no site institucional do MEC que, a partir de 2017, ocorreriam mudanças no Enem, inclusive a suspensão de certificação do Ensino Médio. Endereço: http://www.brasil.gov.br/educacao/2016/11/ novo-enem-nao-deve-certificar-conclusao-do-ensino-medio Acesso em: 11/mar/2017. 
indicar a qual instituição seria solicitada no momento da inscrição, e, para fazer jus ao certificado de Ensino Médio, deveria atender aos seguintes requisitos: a) indicar a pretensão de utilizar os resultados de desempenho no exame para fins de certificação de conclusão do Ensino Médio, no ato da inscrição, bem como a instituição certificadora; b) estar com no mínimo 18 (dezoito) anos completos na data da primeira prova de cada edição do exame; c) atingir o mínimo de 450 (quatrocentos e cinquenta) pontos em cada uma das áreas de conhecimento do exame; d) atingir o mínimo de 500 (quinhentos) pontos na redação.

O Ideb e o Enem são fortemente utilizados como parâmetros para a formulação ou, como no caso do Ensino Médio, reformulação de políticas. Como já foi posto por Afonso $(1999,2012)$, ambas as avaliações tratam de responsabilização pelos resultados das escolas e dos próprios estudantes. Além disso, unificando em nível nacional os resultados de unidades federativas tão distantes entre si, tanto em termos de recursos como de investimentos nas diversas áreas sociais e em especial na educação, esses sistemas avaliativos acabam por dar um resultado distante da realidade local de estados e municípios, dificultando a possibilidade de que a utilização desses dados seja coerente com a necessidade da população.

Pode-se retirar uma reflexão pertinente acerca dessa discussão, do início do documento A meritocracia na educação brasileira, presente na Revista Retratos da Escola, da Escola de Formação da Confederação Nacional dos Trabalhadores em Educação (CNTE):

A globalização acirrou a competitividade entre países e empresas e a educação passou a ser sinônimo de produtividade. As dimensões humana, cultural, artística e filosófica, que delineiam a formação para a cidadania - um dos objetivos do art. 205 da Constituição Federal -, têm dado lugar, exclusivamente, ao preparo para o trabalho, sem se preocupar com a autonomia e a felicidade dos sujeitos (ESCOLA DE FORMAÇÃo DA CONFEDERAÇÃo NACIONAL DOS TRABALHADORES EM EdUCAÇÃo, 2007, p. 209).

O fator competitivo é a essência da meritocracia e a característica fundamental da ideologia neoliberal. Esse passou a perpassar a Educação Básica, visto que educadores e estudantes são cobrados, sem a contrapartida que Ihes garanta valorização e qualidade da educação com equidade. Para a CNTE, a meritocracia neoliberal escamoteia as desigualdades nos sistemas de educação e tira o foco das condições de aprendizagem dos estudantes e de trabalho dos educadores, para induzir o senso comum a acreditar no mérito individual dos sujeitos. $\mathrm{O}$ documento denuncia ainda que a estratégia liberal para as avaliações escolares, que consiste na individualização do mérito, foca claramente a privatização das escolas públicas 


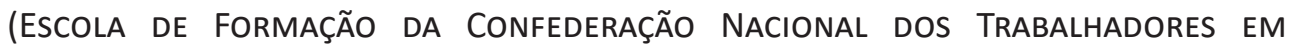
EDUCAÇÃo, 2007), ademais postula:

[...] Não queremos ranquear ninguém, tampouco deixar alguém para trás. Precisamos, sim, acabar com o analfabetismo, regularizar o fluxo escolar, universalizar a escola integral e de tempo integral, valorizar os profissionais, implantar a gestão democrática em todos os sistemas e escolas públicas e garantir financiamento compatível para a implantação do custo aluno-qualidade.

Nossa visão de educação contempla um sistema de avaliação diagnóstico, reflexivo e indutor de melhorias na política educacional e de valorização para os educadores (professores e funcionários) (ESCOLA DE FORMAÇÃo DA Confederação NACIONAL dos Trabalhadores EM EducaçÃo, 2007, p. 212).

Por fim, é isso que o documento declara, e retrata com clareza o pensamento da CNTE.

\section{Medida Provisória no 746/2016 e a Lei no 13.415/2016: inovação no Ensino Médio?}

Em um processo de tramitação extremamente célere no Congresso Nacional, a Medida Provisória no 746, de 22 de setembro de 2016, que institui a política de fomento à implementação de escolas de Ensino Médio em tempo integral, altera a Lei no 9.394, de 20 de dezembro de 1996, que dispõe sobre as diretrizes e bases da educação nacional, e a Lei no 11.494 de 20 de junho de 2007, que regulamenta o Fundo de Manutenção e Desenvolvimento da Educação Básica e de Valorização dos Profissionais da Educação, e dá outras providências, converte-se na Lei no 13.415, de 16 de fevereiro de 2017.

Da exposição de motivos apresentada pelo Ministro da Educação José Mendonça Bezerra Filho ao Presidente da República (EM no 00084/2016/MEC), destacam-se alguns pontos:

[...] 4. Atualmente o ensino médio possui um currículo extenso, superficial e fragmentado, que não dialoga com a juventude, com o setor produtivo, tampouco com as demandas do século XXI. Uma pesquisa realizada pelo Centro Brasileiro de Análise e Planejamento - CEBRAP, com o apoio da Fundação Victor Civita - FVC, evidenciou que os jovens de baixa renda não veem sentido no que a escola ensina (BRASIL, 2016a, p. 1).

A indicação dada é que a juventude pobre não está na escola por ela não ser atrativa, e não pelos diversos motivos apresentados em estudos sobre a evasão escolar (entre os quais: CASTRO; SANTOS; BARBALHO, 2014; Fundo DAS NAçõES 
UNIDAS PARA A INFÂNCIA, 2009). Esses estudos apontam que alguns obstáculos se apresentam na vida escolar de crianças e adolescentes, como aqueles de ordem sociocultural e econômica, vinculados à oferta educacional; e de ordem financeira e técnica - podendo todas essas barreiras se manifestarem combinadamente, dificultando que as crianças passem de ano, permaneçam na escola, ou mesmo tenham o seu direito de progredir e concluir a Educação Básica na idade certa.

Segundo o Fundo das Nações Unidas para a Infância - Unicef (2009), os obstáculos econômicos encontrados envolvem a necessidade de os jovens contribuírem para a renda familiar desde cedo, ou simplesmente não terem condições materiais de permanecer na escola. Com relação à oferta educacional, muitos fatores estão relacionados à falta de adequação curricular, de professores capacitados e de sua valorização, bem como ao número insuficiente de escolas, à falta de acessibilidade para alunos com deficiência e às condições precárias de infraestrutura. Os obstáculos de ordem financeira e técnica envolvem a insuficiência de recursos na área educacional. Os obstáculos socioculturais, por sua vez, estão relacionados à discriminação racial, à exposição à violência, à gravidez não planejada na adolescência, entre outros fatores.

[...] 8. O Brasil utiliza o Índice de Desenvolvimento da Educação Básica IDEB para avaliar a aprendizagem dos alunos. Esse índice leva em consideração o fluxo escolar (taxa de aprovação, evasão e abandono), a nota da Prova Brasil para ensino fundamental e a nota do Sistema de Avaliação da

Educação Básica - SAEB para o ensino médio. Na criação do IDEB, o Brasil definiu alcançar o índice 5,2 em 2021 com metas progressivas a cada dois anos. Essa meta está relacionada ao resultado obtido pelos 20 países mais bem colocados no mundo, que compõem a Organização para Cooperação e Desenvolvimento Econômico - OCDE.

9. Nos resultados do SAEB, o ensino médio apresentou resultados ínfimos. Em 1995, os alunos apresentavam uma proficiência média de 282 pontos em matemática e, hoje, revela-se o índice de 267 pontos, ou seja, houve uma queda de 5,3\% no desempenho em matemática neste período. Os resultados tornam-se mais preocupantes, observado o desempenho em língua portuguesa: em 1995, era 290 pontos e, em 2015, regrediu para 267 uma redução de $8 \%$.

10. Neste período, o Brasil passou pela democratização da educação, com a universalização da oferta de matrícula na educação básica e, embora não tenha conseguido atender a todos os alunos do ensino médio, 58\% dos jovens de 15 a 17 anos estão na escola. Contudo, a qualidade do ensino ofertado, além de não acompanhar o direito ao acesso, decresceu, uma vez verificados os resultados de aprendizagem apresentados (BRASIL, 2016a, p. 1-2, grifo nosso). 
Castro, Santos e Barbalho (2014) destacam que a palavra qualidade tradicionalmente se refere a características, atributos ou propriedades que os sujeitos imputam a algo, mas quando se trata de definir a qualidade de uma escola ou de um sistema de ensino, o termo extrapola o sentido mais simples do caracterizar e passa a ter um sentido mais político, pois implica definir a finalidade do processo educativo, questionando-se: a quem a educação serve? O que se valoriza socialmente? Desse modo, essas definições traduzem o direcionamento das ações. Para esses autores, a classe dominante atribui à qualidade da educação o acesso aos conhecimentos construídos e valorizados por esse próprio grupo, utilizados como distinção de classe e como meio de organização para a manutenção da hegemonia. Para setores mais progressistas, a qualidade da educação escolar tem uma perspectiva social, atribuindo-Ihe o fato de ser unitária, omnilateral, politécnica e imprescindível às sociedades atuais, sejam essas capitalistas ou não.

A educação escolarizada deveria, então, possibilitar que todos pudessem ler, analisar e compreender o funcionamento do mundo natural e da matéria, as relações sociais, políticas e culturais. Esses setores mais progressistas historicamente lutam por maior participação social nas decisões político-educacionais e pela democratização do acesso das classes trabalhadoras à escola, entendendo o acesso não só como garantia de vaga, mas também como condições de permanência e de conclusão da escolaridade. Pesquisadores da educação profissional, nesse sentido, também destacam a dualidade histórica que envolve a educação e o trabalho, enfatizando a importância de uma perspectiva mais humana na educação: Kuenzer (2002); Moura (2010, 2013a, 2013b); Frigotto (2010); Ramos (2013); Lima Filho (2013); Azevedo (2016); Azevedo, Tavares e Morais (2013); Grabowski e Ribeiro (2010).

[...] 12. O IDEB do ensino médio no Brasil está estagnado, pois apresenta o mesmo valor $(3,7)$ desde 2011. No período de 2005 a 2011, apresentou um pequeno aumento de $8 \%$ e, de 2011 a 2015, nenhum crescimento. O IDEB 2015 está distante $14 \%$ da meta prevista $(4,3)$ e $28,8 \%$ do mínimo esperado para 2021 (5,2). A situação piora quando se analisa o desempenho por unidade federativa, em que somente dois estados, Amazonas e Pernambuco, conseguiram atingir a meta prevista para 2015.

13. Isso é reflexo de um modelo prejudicial que não favorece a aprendizagem e induz os estudantes a não desenvolverem suas habilidades e competências, pois são forçados a cursar, no mínimo, treze disciplinas obrigatórias que não são alinhadas ao mundo do trabalho, situação esta que, aliada a diversas outras medidas, esta proposta visa corrigir, sendo notória, portanto, a relevância da alteração legislativa (BRASIL, 2016a, p. 2). 
Ainda que no ponto 12 se mencionem dados por estado, o parâmetro indicado para o baixo desempenho do Ensino Médio é o resultado nacional do Ideb, visando ao exclusivo aumento de indicadores estatísticos de qualidade. Na sequência, o documento expressa enfaticamente que esse resultado negativo é reflexo do modelo vigente de educação, que seria excessivo e desalinhado com uma formação adequada para "o mundo do trabalho", desconsiderando aspectos gerais essenciais para a formação do Ensino Médio além do trabalho, como ciência, cultura e tecnologia. $\mathrm{E}$, ainda, há que se questionar qual a formação necessária para o mundo do trabalho a que o Ministro se refere: uma que adestre o estudante para quando for trabalhador realizar mecanicamente o que lhe é solicitado, ou uma formação que Ihe possibilite refletir sobre o processo produtivo, sobre as relações na sociedade capitalista, sobre as desigualdades produzidas pela divisão social do trabalho, sobre as questões ambientais que perpassam as questões econômicas na divisão social do trabalho.

Há de se suspeitar que as concepções de trabalho salientadas na exposição de motivos caminham para uma perspectiva revisitada da gerência científica de Frederick Taylor, cujos princípios passavam pela separação de trabalho mental e manual: o objetivo era separar a concepção do trabalho da execução, em um processo que desumanizava o trabalho, tornando-o isento de propósito para o trabalhador. A concepção do trabalho passa a ser da gerência - uma vez que, como bem argumentou Taylor, só quem possui tempo e dinheiro pode estudar o trabalho, e o trabalhador, por sua vez, só tem tempo para realizar o trabalho para garantir sua sobrevivência (BRAVERMAN, 1977).

$\mathrm{Na}$ acumulação flexível também se restabelece a dialética entre o saber e o fazer, quando a competência é concebida como a capacidade para resolver situações não previstas e até mesmo desconhecidas, para o que se articulam conhecimentos tácitos e científicos; mais do que à memorização, essa forma de ver a competência remete à criatividade, capacidade comunicativa e educação continuada. Desse modo, é importante observar que o conhecimento tácito não desaparece para dar lugar ao conhecimento científico, mas sim se restabelece a dialética teoria e prática, passando a competência a assumir a dimensão de prática (KUENZER, 2008).

De fato, há diversos pontos da exposição de motivos que podem ser questionados, mas ao fazê-lo, fugiríamos do objetivo deste trabalho. A seguir, discutiremos um ponto-chave da Lei no 13.415/2017, que resultou da aceitação da exposição de motivos anteriormente apresentada e da consequente aprovação da MP no 746/2016:

Art. 40 O art. 36 da Lei no 9.394, de 20 de dezembro de 1996, passa a vigorar com as seguintes alterações: 
"Art. 36. O currículo do ensino médio será composto pela Base Nacional Comum Curricular e por itinerários formativos, que deverão ser organizados por meio da oferta de diferentes arranjos curriculares, conforme a relevância para o contexto local e a possibilidade dos sistemas de ensino, a saber:

I - linguagens e suas tecnologias;

II - matemática e suas tecnologias;

III - ciências da natureza e suas tecnologias;

IV - ciências humanas e sociais aplicadas;

$\checkmark$ - formação técnica e profissional.

$\S 1$ 10 A organização das áreas de que trata o caput e das respectivas competências e habilidades será feita de acordo com critérios estabelecidos em cada sistema de ensino.

I - (revogado);

II - (revogado);

§ 3 A critério dos sistemas de ensino, poderá ser composto itinerário formativo integrado, que se traduz na composição de componentes curriculares da Base Nacional Comum Curricular - BNCC e dos itinerários formativos, considerando os incisos I a V do caput.

$\S 5$ o Os sistemas de ensino, mediante disponibilidade de vagas na rede, possibilitarão ao aluno concluinte do ensino médio cursar mais um itinerário formativo de que trata o caput.

[...]

$\S 12$. As escolas deverão orientar os alunos no processo de escolha das áreas de conhecimento ou de atuação profissional previstas no caput." (NR) (BRASIL, 2017).

Uma das principais mudanças apresentadas na reforma do Ensino Médio trata da possibilidade de o estudante optar por um itinerário formativo dentre os especificados no artigo 4․ Os argumentos voltados para a indicação de que a evasão escolar e os baixos resultados do Ideb estão relacionados com a falta de interesse dos estudantes em cursar o Ensino Médio resultaram em uma formação em que o estudante, no terceiro ano, possa se dedicar unicamente a disciplinas relacionadas ao seu itinerário formativo. Dessa forma, os estudantes poderiam, já no Ensino Médio, focar em suas futuras áreas de atuação profissional - nas quais, obviamente, seguiriam em seu itinerário formativo no Nível Superior. A possibilidade de focar na área de atuação profissional também possibilitaria um melhor preparo para a realização do Enem.

Com essas mudanças, o Ensino Médio perde sua distinção. Saviani (2007, p. 161) sinaliza que o horizonte que deve orientar a organização do Ensino Médio é 
propiciar aos estudantes "o domínio dos fundamentos das técnicas diversificadas utilizadas na produção, e não o mero adestramento em técnicas produtivas. Não a formação de técnicos especializados, mas de politécnicos ${ }^{81}$. Nesse horizonte, os estudantes de Ensino Médio teriam acesso às modalidades fundamentais que dão base à multiplicidade de processos e técnicas de produção existentes. A reforma do Ensino Médio caminha na direção oposta: com o objetivo de se tornar mais "atraente", sob o signo de ser uma proposta inovadora, os conhecimentos científicos fundamentais que dão base à produção de um modo geral serão divididos em cinco áreas diferentes, o estudante pode escolher em que área do conhecimento irá se especializar. A visão não é mais de uma formação geral, e sim de uma formação especializada para o trabalho.

Considerando que a organização das áreas de conhecimento vai ficar a critério de cada sistema de ensino, ocasionalmente, especialmente nas escolas fora dos grandes centros, os estudantes não terão a possibilidade de optar pelo itinerário formativo com que se identificam; possivelmente terão que cursar o que estiver disponível.

Outra problemática é a formação técnica e profissional. A lei ignora enfaticamente a existência do Ensino Médio Integrado nas instituições federais de ensino médio, que já oferece uma formação profissional de nível médio aliada a uma formação que caminha para a perspectiva de politecnia assinalada por Saviani (2007); para aqueles estudantes em que a necessidade de entrada no mundo do trabalho urge, terão a formação profissional técnica de nível médio; e para aqueles que queiram prosseguir na área de estudo ou queiram adentrar no Nível Superior em outra área profissional, a formação possibilitada pelos institutos federais também possibilitará esse percurso.

Com esse novo formato, os estudantes que necessitarem entrar no mundo do trabalho mais cedo e optarem pela área de formação técnica e profissional não terão acesso às demais áreas de conhecimento. Voltamos, então, à dicotomia da educação para ricos (que continuarão seus itinerários formativos visando ao ensino superior) e para pobres (que precisam entrar mais rapidamente no mercado de trabalho, e para tanto irão optar pelo ensino de técnicas específicas que possibilitem essa entrada rápida).

Observam-se, por meio dessa reflexão, confluências entre a reforma do Ensino Médio do Governo Temer e a reforma de 1ㅇ e 2으 Graus de 1971 em termos da formação dos jovens e a aceitação da reforma por instituições públicas e privadas. Moura (2010), ao discutir a dualidade histórica e as possibilidades de integração do

${ }^{8}$ Politecnia é entendida, nesse trabalho de Saviani, como especialização como domínio dos fundamentos científicos das diferentes técnicas utilizadas na produção moderna (SAVIANI, 2007, p. 161). 
Ensino Médio com a Educação Profissional, faz um resumo da história da Educação Profissional e do Ensino Médio do país, tomando como categoria estruturante a dualidade que sempre esteve presente na educação básica entre cultura geral e cultura técnica; entre formação acadêmica/academicista e formação profissional/ para o mercado de trabalho.

Nesse resgate histórico, Moura (2010) retoma a Lei $\mathrm{n}$ ㅇ 5.692, de 11 de agosto de 1971, já revogada, que fixava as diretrizes e bases para o ensino de 1ㅇ e 2음 Graus. Em um contexto de ditadura militar, os investimentos em educação se destinavam a alavancar o desenvolvimento econômico brasileiro, sendo a educação utilizada como meio de inculcação da ideologia do governo autoritário. Nessa conjuntura, a Lei da Reforma do Ensino de 1ㅇ e 2ㅇ graus é promulgada, numa tentativa de estruturar a educação de nível médio brasileiro como sendo profissionalizante para todos. Moura (2010) destaca alguns fatores que conduziram a essa obrigatoriedade da profissionalização: o interesse do governo autoritário em elevar seus índices de aceitação popular dando respostas à crescente demanda das classes populares por acesso a níveis mais elevados de escolarização, o que culminava em forte pressão por aumento de vagas no nível superior.

Outro fator era que aquele governo tinha como projeto econômico o desenvolvimento construído com base em endividamento externo para financiar a industrialização do país; esse projeto demandava mão de obra qualificada para atender o crescimento econômico, o que justificava a reforma empreendida.

Desse modo, sob esses dois fatores, a resposta do governo autoritário foi criar uma solução diferente para a demanda das classes populares por elevação de escolarização, pautando-se na necessidade criada por mão de obra pelo crescimento econômico - o chamado "milagre brasileiro". A formação técnica profissionalizante em nível de 2 ․ Grau "garantiria" a possibilidade de inserção no "mercado de trabalho".

O que se observou de fato com a promulgação da lei foi que, na prática, a obrigatoriedade só atingiu os sistemas públicos de ensino, em particular as redes estaduais e federal. Enquanto isso, as escolas privadas prosseguiram com currículos propedêuticos voltados para as ciências, letras e artes, visando ao atendimento às elites, e possibilitando os conhecimentos gerais necessários para uma aprovação no vestibular. A reforma foi simplesmente descartada pela rede privada (com raras exceções), devido ao seu elevado custo (GERMANo, 2005 apud MourA, 2010).

Nos sistemas estaduais de ensino, observou-se uma série de problemas na implantação do ensino profissionalizante a partir de 1971: a inclusão da formação profissional no currículo acabava por seguir uma tendência de empobrecimento da formação geral do estudante. Com o aumento de conteúdos sem aumento da 
carga horária total do nível de ensino, assim, o que saiu prejudicado foi a formação geral, pois a formação para o trabalho assumiu um caráter instrumental e de baixa complexidade, uma vez que a base científica que permitiria a compreensão de conhecimentos complexos inerentes ao mundo do trabalho foi suprimida. Outro problema observado foi a falta de investimento na formação de professores, o que fez com que os sistemas estaduais buscassem formações que não acarretassem custos com laboratórios, equipamentos ou infraestrutura em geral. Assim, proliferaram cursos técnicos de administração, secretariado e contabilidade, provocando uma saturação desses profissionais e, posteriormente, a banalização e o desprestígio dessas profissões (MourA, 2010).

$O$ resultado que se observou com a reforma foi um movimento dos filhos da classe média das escolas públicas para as escolas privadas, na busca de uma formação que os preparasse para a entrada no Ensino Superior (MoURA, 2010). Esse movimento foi crucial para a desvalorização da escola pública estadual e municipal, pois era e continua sendo a classe média que tem algum poder de pressão para a melhoria da qualidade da educação junto às esferas do governo, e a saída dela da escola pública limita seu poder de barganha junto aos poderes instituídos.

\section{Considerações finais}

Dado o exposto neste artigo, a conclusão a que chegamos é que a reforma do Ensino Médio não foi pautada nas necessidades reais da população brasileira, como resultado de debates que já vinham ocorrendo, por meio das conferências nacionais de educação (2009, 2014), entre outros fóruns específicos, como a Associação

Nacional de Pesquisadores em Educação e o Fórum Nacional de Educação, entre outros associados à agenda da política educacional brasileira. Isso pode ser verificado nos documentos regulamentadores conforme expostos.

Quanto à relação do Brasil com as concepções de Estado-avaliador, este se enquadra na segunda fase, posto que, para a reforma do Ensino Médio, ancorouse em resultados de avaliação que não consideram as características locais e a demanda por conhecimentos pertinentes às sociedades atuais, camuflando a reforma pelo viés da inovação, de acordo com o discurso justificador e sem respeitar o pensamento dos que fazem e lutam por educação no país, como o da CNTE.

Desse modo, vimos que as análises indicam que não há perspectiva de que a reforma do Ensino Médio efetivamente seja inovadora e transformadora da realidade da educação pública, com vistas ao cumprimento dos objetivos e metas do Plano Nacional de Educação (2014-2024), sobretudo na perspectiva da qualidade social da educação. 
Considerando a Lei $\mathrm{n}$ 0 5.692/1971, pondera-se que a proposta ora apresentada pela Lei no 13.415/2017 é de fato uma "inovação" na perspectiva da transformação e da garantia da qualidade social da educação em termos de discurso, mas contraditoriamente conflui para as mesmas consequências em relação à formação dos jovens e a não assunção desta pelas escolas privadas. Naquele momento, os sistemas oficiais de ensino, nomeadamente os estaduais e municipais, não foram capazes de realizar a contento a proposta implementada na conjuntura da ditadura, além de sobrecarregar o mercado com profissionais técnicos sob a promessa de garantia de emprego, como, inclusive, ainda ocorre hoje, no que diz respeito à implementação do Programa Brasil Profissionalizado.

Por fim, por suas influências vinculadas às perspectivas neoliberais, a reforma do Ensino Médio vem para destacar a meritocracia na educação brasileira, acentuando o elemento competitividade característico dessa ideologia, confluindo para uma educação que reforça as desigualdades sociais no país, notadamente dos jovens da classe trabalhadora.

\section{Referências bibliográficas}

Afonso, A. J. Estado, mercado, comunidade e avaliação: esboço para uma rearticulação crítica. Revista Educação \& Sociedade, Ano XX, n. 69, p. 139-164, dez. 1999.

AFONSO, A. J. Avaliação Educacional: regulação e emancipação. (Para uma sociologia das políticas avaliativas contemporâneas). 4. ed. São Paulo: Cortez, 2009.

Afonso, A. J. Para uma conceptualização alternativa de accountability em educação. Educação e Sociedade, Campinas, v. 33, n. 119, p. 471-484, abr.-jun. 2012.

Afonso, A. J. Mudanças no Estado-avaliador: comparativismo internacional e teoria da modernização revisitada. Revista Brasileira de Educação, v. 18, n. 53, p. 267-284, abr-jun 2013.

Azevedo, M. A; TAvares, A. M. B. N; Morais, P. S. Desafios ao trabalho como princípio educativo: a realidade no ensino médio (noturno) em escola pública do Rio Grande do Norte. In: MourA, D. H. (Org.). Produção de conhecimento, políticas públicas e formação docente em educação profissional. Campinas: Mercado de Letras, 2013.

Azevedo, M. A. Uma década do Decreto no 5.154/2004 e do PROEJA: notas do debate. Revista Holos, Natal: IFRN, Ano 32, v. 6, p. 89-99, 2016.

BRASIL. Lei no 5.692, de 11 de agosto de 1971. Fixa Diretrizes e Bases para o ensino de 10 e 2 o graus, e dá outras providências. (Revogada pela Lei no 9.394/1996). Diário Oficial da União. Brasília, DF, 11 ago. 1971. Disponível em: <http://www.planalto. gov.br/ccivil_03/leis/L5692.htm> Acesso em: 11/mar/2017.

BRASIL. Portaria MEC no 10, de 20 de maio de 2012. Dispõe sobre certificação de conclusão do ensino médio ou declaração de proficiência com base no Exame Nacional do Ensino Médio-ENEM. Diário Oficial da União. Brasília, DF, 20 mai. 
2012. Disponível em: <http://download.inep.gov.br/educacao_basica/enem/ legislacao/2012/portaria-MEC10-certificacao.pdf> Acesso em: 12/mar/2017.

BRASIL. Portaria INEP no 179, de 28 de abril de 2014. Dispõe sobre o processo de certificação, as competências das Instituições Certificadoras e do INEP e os requisitos necessários à obtenção de certificado de conclusão do Ensino Médio e declaração parcial de proficiência com a utilização dos resultados de desempenho obtidos no Exame Nacional do Ensino Médio - ENEM. Diário Oficial da União. Brasília, DF, 28 abr. 2014. Disponível em: <http://download.inep.gov.br/educacao_basica/ enem/legislacao/2014/portaria_n179_dispoe_sobre_processo_certificacao_ competencias.pdf> Acesso em: 12/mar/2017.

BRASIL. Ministério da Educação. EM no 00084/2016/MEC. Exposição de motivos para Medida Provisória no 746/2016. Brasília, DF, 15 set. 2016a. Disponível em: <https:// www.planalto.gov.br/ccivil_03/_ato2015-2018/2016/Exm/Exm-MP-746-16.pdf> Acesso em: 11/mar/2017.

BRASIL. Medida Provisória no 746, de 22 de setembro de 2016. Institui a Política de Fomento à Implementação de Escolas de Ensino Médio em Tempo Integral, altera a Lei $n$ o 9.394, de 20 de dezembro de 1996, que estabelece as diretrizes e bases da educação nacional, e a Lei no 11.494 de 20 de junho 2007, que regulamenta o Fundo de Manutenção e Desenvolvimento da Educação Básica e de Valorização dos Profissionais da Educação, e dá outras providências. Diário Oficial da União. Brasília, DF, 22 set. 2016b. Disponível em: <http://www.planalto.gov.br/ccivil_03/_Ato20152018/2016/Mpv/mpv746.htm> Acesso em: 03/jan/2016.

BRASIL. Lei no 13.415, de 16 de fevereiro de 2017. Altera as Leis no 9.394, de 20 de dezembro de 1996, que estabelece as Diretrizes e Bases da Educação Nacional, e 11.494, de 20 de junho 2007, que regulamenta o Fundo de Manutenção e Desenvolvimento da Educação Básica e de Valorização dos Profissionais da Educação, a Consolidação das Leis do Trabalho - CLT, aprovada pelo Decreto-Lei no 5.452, de 1응 de maio de 1943, e o Decreto-Lei no 236, de 28 de fevereiro de 1967; revoga a Lei no 11.161, de 5 de agosto de 2005; e institui a Política de Fomento à Implementação de Escolas de Ensino Médio em Tempo Integral. Diário Oficial da União. Brasília, DF, 16 fev. 2017. Disponível em: < http://www.planalto.gov.br/ccivil_03/_ato20152018/2017/lei/L13415.htm> Acesso em: 11/mar/2017.

BRAVERMAN, H. Trabalho e capital monopolista: a degradação do trabalho no século XX. 3. ed. Trad. Nathanael C. Caixeiro. Rio de Janeiro: Zahar, 1977. p. 49-134.

CAstro, A. M. D. A; SAntos, L. T. G; Barbalho, M. G. C. Qualidade da educação, democratização do acesso, permanência e avaliação: os desafios da educação brasileira. In: FrançA, M; MoMo, M. (Orgs.). Processo democrático participativo: a construção do PNE. Campinas: Mercado de Letras, 2014.

DALE, R. Globalização e educação: demonstrando a existência de uma "cultura educacional mundial comum" ou localizando uma "agenda globalmente estruturada para a educação"? Revista Educação \& Sociedade, Campinas: CEDES, v. 25, n. 87, p. 423-460, 2004.

ESCOLA DE FORMAÇÃO dA CONFEDERAÇÃo NACIONAL dOS TRABALHADORES EM EduCAÇÃo (ESFORCE). Revista Retratos da Escola, v. 7, n. 12, p. 210-214, jan/jun, 2013. 
FRIGOTTO, G. A relação da educação profissional e tecnológica com a universalização da educação básica. In: MolL, J. (Org.). Educação profissional e tecnológica no Brasil contemporâneo: desafios, tensões e possibilidades. Porto Alegre: Artmed, 2010.

GraboWSKI, G; RIBEIRo, L. A. R. Reforma, legislação e financiamento da educação profissional no Brasil. In: MolL, J. (Org.). Educação profissional e tecnológica no Brasil contemporâneo: desafios, tensões e possibilidades. Porto Alegre: Artmed, 2010.

instituto Nacional de Estudos E Pesquisas Educacionais Anísio Teixeira (INEP). Ministério da Educação. Site institucional do INEP. Educação Básica. Disponível em: <http://portal.inep.gov.br/educacao-basica> Acesso em: 11/mar/2017.

KUENZER, A. Z. Exclusão includente e inclusão excludente: a nova forma de dualidade estrutural que objetiva as novas relações entre educação e trabalho. In: LOMBARDI, J. C.; SANFElICE, J. L.; SAVIANI, D. (Orgs.). Capitalismo, trabalho e educação. Campinas: Autores Associados, HISTEDBR, 2002.

KUENZER, A. Z. Mesa redonda: formação de professores para a educação profissional e tecnológica: perspectivas históricas e desafios contemporâneos. In: FoRMAÇÃo DE Professores para Educação Profissional e TeCnológica, Brasília, 26, 27 e 28 de setembro de 2006 - Brasília: INEP, 2008.

LIMA FILHO, D. L. Políticas públicas para a educação profissional e EJA nos anos 2000: sentidos contraditórios da expansão e da redefinição institucional. In: MouRA, D. H. (Org.). Produção de conhecimento, políticas públicas e formação docente em educação profissional. Campinas: Mercado de Letras, 2013.

MourA, D. H. Ensino médio e educação profissional: dualidade histórica e possibilidades de integração. In: MoLL, J. (Org.). Educação profissional e tecnológica no Brasil contemporâneo: desafios, tensões e possibilidades. Porto Alegre: Artmed, 2010.

MourA, D. H. Ensino médio e educação profissional no Brasil dos anos 2000: movimentos contraditórios. In: MourA, D. H. (Org.). Produção de conhecimento, políticas públicas e formação docente em educação profissional. Campinas: Mercado de Letras, 2013a.

MourA, D. H. Mudanças na sociedade brasileira dos anos 2000 limitadas pela hegemonia do neoliberalismo: implicações para o trabalho e para a educação. In: Moura, D. H. (Org.). Produção de conhecimento, políticas públicas e formação docente em educação profissional. Campinas: Mercado de Letras, 2013b.

RAMOS, M. P; SCHABRACH, L. M. O estado da arte da avaliação de políticas públicas: conceituação e exemplos de avaliação no Brasil. Revista de Administração Pública, v. 45, n. 6, p. 1272-1294, set./out. 2012.

RAMos, M. Trabalho e educação: implicações para a produção do conhecimento em educação profissional. In: MouRA, D. H. (Org.). Produção de conhecimento, políticas públicas e formação docente em educação profissional. Campinas: Mercado de Letras, 2013.

RAVITCH, D. Vida e morte do grande sistema escolar americano: como os testes padronizados e o modelo de mercado ameaçam a educação. Porto Alegre: Sulina, 2011. 
SANTOS, B. S. O Estado, a sociedade e as políticas sociais: o caso das políticas de saúde. Revista Crítica de Ciências Sociais, n. 23, p. 13-74, set. 1987.

SAntos, B. S. Ciência. In: CARrilho, M. (org.) Dicionário do Pensamento Contemporâneo. Lisboa: Dom Quixote, pp. 23-24, 1991.

SAntos, B. S. Pela mão de Alice: o social e o político na pós-modernidade. 13. ed. São Paulo: Cortez, 2010.

SAVIANI, D. Trabalho e educação: fundamentos ontológicos e históricos. Revista Brasileira de Educação., v. 12, n. 34, p. 152-165, jan./abr. 2007.

SILVA, F. N. Ensino médio integrado à educação profissional: a implementação do Programa Brasil Profissionalizado em Mossoró-RN. 2016. 156f. Dissertação (Mestrado em Educação Profissional) - Instituto Federal de Educação, Ciência e Tecnologia da Rio Grande do Norte. Programa de Pós-Graduação em Educação Profissional, 2015.

SzTOMPKA, P. A sociologia da mudança social. Rio de Janeiro: Civilização Brasileira, 2005.

\section{Fabiana Teixeira Marcelino}

Doutoranda e Mestre em Educação pelo Programa de Pós-Graduação em Educação Profissional do Instituto Federal de Educação, Ciência e Tecnologia do Rio Grande do Norte (IFRN). Atualmente é psicóloga escolar no IFRN-Campus Natal, Cidade Alta. Contato: fabianatm@gmail.com

\section{Shilton Roque dos Santos}

Mestre em Educação pelo Programa de Pós-Graduação em Educação Profissional, do Instituto Federal de Educação, Ciência e Tecnologia do Rio Grande do Norte (IFRN). Atualmente é assistente em administração e pesquisador do IFRN. Contato: shiltonroque@gmail.com

\section{Márcio Adriano de Azevedo}

Doutor em Educação pela Universidade Federal do Rio Grande do Norte. Atualmente Pró-Reitor de Pesquisa e Inovação e professor do Instituto Federal de Educação, Ciência e Tecnologia do Rio Grande do Norte (IFRN) e exerce a função de Pró-Reitor de Pesquisa e Inovação do IFRN. Contato: marcio.azevedo@ifrn.edu.br

\section{Lenina Lopes Soares Silva}

Doutora em Ciências Sociais pela Universidade Federal do Rio Grande do Norte (UFRN). Atualmente é professora no Programa de Pós-Graduação em Educação Profissional, na Licenciatura em Física e em Matemática do Instituto Federal de Educação, Ciência e Tecnologia do Rio Grande do Norte (IFRN). Contato: lenina.lopes@ifrn.edu.br 
DRSP 